\title{
CONTRIBUIÇÕES DA PRÁTICA DO IOGA NA CONDIÇÃO DE SAÚDE, ATITUDES E COMPORTAMENTOS DE MULHERES ADULTAS E IDOSAS
}

\author{
YOGA'S CONTRIBUTIONS TO HEALTH CONDITIONS, ATTITUDES AND \\ BEHAVIORS OF ADULT AND ELDERLY WOMEN
}

\section{CONTRIBUCIONES DE LA PRÁCTICA DEL YOGA EN LAS CONDICIONES DE SALUD, ACTITUDES Y COMPORTAMIENTOS DE MUJERES ADULTAS Y DE LA TERCERA EDAD}

\section{Julio Mizuno*, Jeniffer Zanetti Brandani**, Silvia Deutsch*, Fernanda Rossi**, Henrique Luiz Monteiro**}

Palavras chave:

loga.

Atitude.

Comportamento

Saúde.

Keywords:

Yoga.

Attitude.

Behavior.

Health.

Palabras clave:

Yoga.

Actitud.

Comportamiento. Salud.
Resumo: Este estudo analisa as percepções de mulheres adultas e idosas sobre as mudanças nas condições de saúde, atitudes e comportamentos, relacionadas à prática de Hatha Yoga. Dez mulheres com idades entre 54 e 72 anos participaram desta pesquisa qualitativa, do tipo descritivo. Foi realizada uma sessão de grupo focal com temas relacionados à prática de ioga, condições físicas, de saúde e doença, social e psicoemocional. Os resultados indicam que o programa proporcionou às mulheres a aprendizagem e incorporação dos ásanas, tornando-as mais conscientes e autônomas nos cuidados com a saúde física. $O$ entendimento dos conceitos filosóficos do ioga refletiu no enfrentamento de situações e problemas pessoais, nas relações familiares e sociais, além de proporcionar um novo olhar sobre si mesmas em relação ao autocuidado e à individualidade. Conclui-se que o ioga, pautado na integralidade do indivíduo, representa um importante recurso terapêutico para a saúde e bem-estar do ser humano.

Abstract: This study looks into adult and elderly women's perceptions about changes in health conditions, attitudes and behaviors related to their practice of Hatha Yoga. Ten women aged 54-72 were included in the qualitative, descriptive study. A focus group session was held with themes related to the practice of yoga, as well as physical, health, illness, social, and psychoemotional conditions. The results indicate that the program provided women with learning and incorporation of asanas, making them more conscious and autonomous in their physical health care. Understanding yoga's philosophical concepts helped them face personal situations and problems in their family and social relations, besides providing them with a new view about themselves regarding self-care and individuality. It concluded that yoga, based on individual wholeness, is an important therapeutic resource for human being's health and well-being.

Resumen: Este estudio analiza las percepciones de mujeres adultas y de la tercera edad acerca de los cambios en las condiciones de salud, actitudes y comportamientos, relacionados con la práctica de Hatha Yoga. Participaron en esta investigación cualitativa, de tipo descriptivo, diez mujeres con edades entre 54 y 72 años. Se realizó una sesión de grupo focal con temas relacionados a la práctica del yoga, condiciones físicas, de salud y enfermedad, social y psicoemocional. Los resultados indican que el programa proporcionó a las mujeres el aprendizaje e incorporación de los asanas, haciéndolas más conscientes y autónomas en el cuidado de la salud física. La comprensión de los conceptos filosóficos del yoga se reflejó en el enfrentamiento de situaciones y problemas personales, en las relaciones familiares y sociales, además de proporcionar una nueva mirada sobre sí misma en relación al autocuidado y a la individualidad. Se concluye que el yoga, pautado en la integralidad del individuo, representa un importante recurso terapéutico para la salud y el bienestar del ser humano.
*Universidade Estadual Paulista. Rio Claro, SP, Brasil. E-mail: juliomizuno@gmail.com; sdeutsch@rc.unesp.br.

**Universidade Estadual Paulista. Bauru, SP, Brasil.

E-mail: jeniffer_brandani@yahoo. com.br;

fernandarossi@fc.unesp.br; heu@fc.unesp.br.

Recebido em: 15-08-2017 Aprovado em: 27-08-2018

DOI https://doi.org/10.22456/1982-8918.75680 (c) (1) () Licence 


\section{INTRODUÇÃO}

A palavra "ioga" deriva do termo sânscrito "yuj" que pode significar "união" ou "disciplina" (KALYAMA, p. 23, 2003). União no sentido de integrar corpo, mente, espírito e emoções, e disciplina como meio para se alcançar essa integralidade. Originário do Vale do Indo há cerca de cinco milênios, o ioga se apropria da metafísica, da cosmologia e da cultura popular hindu para se desenvolver ao longo dos séculos. Por volta de 200 d.C. um sábio indiano de nome Patañjali compilou o Yoga-Sutra, texto considerado fundamental, no qual indica os oito passos do caminho do ioga, sendo eles: yama, nyama, ásana, pranayama, pratyahara, dharana, dhyana, samadhi (FEUERSTEIN, 1998).

Yamas e nyamas são princípios filosóficos universais que direcionam o indivíduo a construir essencialmente valores, virtudes, atitudes e comportamentos que incidam diretamente sobre o respeito por si e pelos outros. Os cinco yamas são: ahimsa (não violência contra a natureza, animais, os outros e contra si mesmo), satya (verdade, não mentir para os outros, nem para si mesmo), asteya (não roubar; válido para itens materiais, ideias, tempo, saúde etc.), brahmacharya (contenção, celibato e equilíbrio da sexualidade) e aparigraha (não acumulação ou desapego em relação a objetos, pessoas, cargos etc.). Já as disciplinas internas, os nyamas, são: saucha (purificação ou limpeza do corpo e dos pensamentos), santosha (prática de contentamento diário e agradecimento por todas as situações), tapas (perseverança e disciplina para o desenvolvimento físico, mental e espiritual), svadhyaya (estudo de si e dos textos relacionados ao ioga) e isvara-pranidhana (entrega ao caminho espiritual) (FEUERSTEIN, 1998). Desse modo, podemos associar os yamas aos comportamentos e os nyamas às atitudes.

Completam os oito passos de Patãnjali: ásana, que significa assento estável e confortável e, atualmente, se refere às posturas de ioga. Engloba elementos de isometria muscular, alongamento, equilíbrio, alinhamento corporal, respiração controlada, foco na consciência corporal, associação com elementos da natureza e personagens da mitologia hindu. O pranayama consiste de exercícios que controlam a frequência respiratória e a expansão torácica como forma de expandir a energia vital (prana). Pratyahara, dharana e dhyana são técnicas de concentração e meditação que conduzem ao silenciar da mente, ao autoconhecimento e à conexão com aspectos espirituais por meio da introspecção. Shamadhi é o ápice do ioga, considerado um estado psicoemocional indescritível de supraconsciência, no qual o indivíduo se torna livre de todas as aflições, sofrimentos e ilusão (FEUERSTEIN, 1998).

Durante o processo de aprendizagem do ioga, desde os princípios básicos até a meditação, o praticante pode experimentar diversos benefícios. Os primeiros a serem observados são os advindos das técnicas físicas de ásanas e pranayamas, como, por exemplo, os descritos por Mizuno et al. (2015), em estudo que explorou as percepções de mulheres adultas e idosas com hipertensão arterial, participantes de um programa de Hatha Yoga com duração de quatro meses (três vezes por semana). Os autores concluíram que a prática promoveu a conscientização e o aumento do autocuidado em relação à alimentação; aumentou a disposição para a realização de atividades cotidianas; diminuiu a queixa de dores, o consumo de medicação e de sinais e sintomas de diversas doenças; além de melhorar o estado de humor, a autoestima e promover reflexões do âmbito social.

Porém, em uma visão ampliada, a prática de ioga visa direcionar a pessoa ao caminho do autoconhecimento, libertando-a dos condicionamentos e do automatismo, para que se possa 
chegar ao estado de felicidade plena, que é obtido pelas práticas relacionadas à interiorização e meditação adquiridas ao longo de um processo de conhecimento e entendimento da filosofia do ioga. Estudo de Sharma, Gupta e Bijlani (2008) demonstrou que oito dias de prática de ioga, complementados por informações sobre nutrição, doenças (as quais alguns pacientes eram acometidos) e gerenciamento do estresse, promoveram um aumento do interesse pela vida, aumento no enfrentamento de situações de crise, diminuição nas preocupações e aumento dos sentimentos de alegria.

Uma metanálise realizada por Buffard et al. (2012) enfatiza que a prática de ioga pode proporcionar efeitos benéficos em aspectos psicossociais em pacientes com câncer, com tamanho de efeito de moderados a grandes para redução no sofrimento, ansiedade, depressão, aumento na qualidade de vida geral e nas funções emocionais e sociais, avaliados por questionários quantitativos.

Um projeto-piloto conduzido na cidade de Campinas/SP com funcionários e alunos de uma universidade pública apresenta resultados benéficos da prática de ioga realizada em um período de quatro meses, para melhora dos sintomas físicos (dor de cabeça, dor nos joelhos, formigamentos das pernas, entre outros), emocionais (ansiedade e estresse) e na percepção de bem-estar (BARROS et al., 2013). Sendo assim, participantes que frequentam programas de ioga podem expressar diferentes percepções relacionadas a essa prática milenar, observáveis em suas atitudes e comportamentos do cotidiano.

Dentre os estudos que envolvem as práticas de ioga, são poucos os que apresentam as percepções dos praticantes por suas próprias falas, normalmente são utilizados questionários fechados, sendo os dados tratados com fundamentação na análise quantitativa (BUFFARD et al., 2012; CHEN et al., 2009; COWEN; ADAMS, 2005). Neste estudo, foi empreendida a perspectiva de análise qualitativa e a técnica de coleta de dados por grupo focal, para possibilitar que as pessoas envolvidas com a prática de ioga pudessem gerar reflexões a respeito de suas atitudes, comportamentos e outros aspectos que julgassem relevantes. Isto posto, o presente estudo teve como objetivo analisar as percepções de mulheres adultas e idosas sobre as mudanças nas condições de saúde, atitudes e comportamentos, relacionadas à prática de Hatha Yoga.

\section{METODOLOGIA}

A pesquisa foi desenvolvida conforme a abordagem qualitativa, baseada no princípio da valorização da "maneira própria de entendimento da realidade pelo indivíduo" (ANDRE, 1995, p. 17), com "esforços concentrados para compreender vários pontos de vista", não houve o objetivo de fazer qualquer "juízo de valor" em relação às opiniões emitidas pelas participantes, "mas, antes, o de compreender o mundo dos sujeitos e determinar como e com que critério eles o julgam" (BOGDAN; BIKLEN, 1999, p. 287).

A pesquisa de campo foi realizada no âmbito do programa "Yoga para Hipertensos", desenvolvido pelo Laboratório de Avaliação e Prescrição de Exercícios do Departamento de Educação Física da Faculdade de Ciências da Universidade Estadual Paulista - campus de Bauru, em atividade desde julho de 2013. O projeto de pesquisa foi aprovado pelo Comitê de Ética em Pesquisa da respectiva universidade (Parecer: 254.378). Os objetivos, os procedimentos de coleta de dados, a garantia do anonimato (com a atribuição de códigos ou 
nomes fictícios quando da divulgação dos resultados) e a autorização para a publicação dos dados fornecidos apenas para fins científicos constaram do Termo de Consentimento Livre e Esclarecido assinado pelas participantes.

O programa consistiu no oferecimento de três aulas semanais do estilo Hatha Yoga, com duração de 90 minutos. Aproximadamente 50 minutos da aula eram dedicados às posturas de ioga, realizadas com atenção constante à respiração e aos limites individuais; enquanto os demais 40 minutos, aos pranayamas, relaxamento induzido, meditação e leitura de textos relacionados à filosofia e história do ioga. Os yamas e nyamas eram trabalhados articuladamente a estes conteúdos. As aulas foram elaboradas pelo mediador do programa e pesquisador deste estudo, formado em Licenciatura Plena em Educação Física e professor de ioga há 15 anos.

O público-alvo foi constituído por mulheres adultas e idosas da comunidade local, preferencialmente usuárias com quadro de hipertensão arterial, acompanhadas pelas unidades municipais de saúde, com o objetivo principal de reduzir a pressão arterial e melhorar a percepção de saúde e bem-estar, bem como contribuir para o aumento das capacidades físicas com a realização das posturas de ioga, que envolviam alongamentos, equilíbrio estático, força isométrica e consciência corporal.

Vinte e três pessoas frequentaram o programa entre julho de 2013 e dezembro de 2014. Para este estudo, foi considerado como critério de inclusão das participantes o tempo mínimo de um ano de frequência regular no programa. As dez mulheres que atendiam a esse critério foram convidadas e concordaram em participar do estudo. As idades variavam entre 54 e 72 anos (média de 63ะ5 anos), oito delas diagnosticadas com hipertensão arterial e com uso regular de anti-hipertensivo, sendo que duas tinham experiência prévia com ioga.

A coleta de dados foi realizada pela técnica de grupo focal, que tem por finalidade aprofundar o conhecimento de um grupo sobre um assunto específico, identificando percepções, sentimentos, atitudes e ideias em relação a um determinado tema (DIAS, 2000). A escolha por esta técnica justifica-se por haver "interesse não somente no que as pessoas pensam e expressam, mas também em como elas pensam e por que pensam". O trabalho com o grupo focal "permite emergir uma multiplicidade de pontos de vista e processos emocionais, pelo próprio contexto de interação criado, permitindo a captação de significados que, com outros meios, poderiam ser difíceis de manifestar" (GATTI, 2005, p. 9). Ainda, Patton (2002) explicita que os dados podem apresentar-se mais fielmente às percepções dos sujeitos que tendem a refletir sobre si mesmos na dinâmica em grupo, possibilitando verificar visões compartilhadas e consistentes.

Assim, o propósito do grupo focal, neste estudo, consistiu em promover insights, como ressalta Morgan (1997), na medida em que as participantes, ao expressarem suas opiniões e sentimentos, poderiam se dar conta de crenças e atitudes presentes em seus comportamentos, bem como aquelas presentes nos comportamentos das outras mulheres, compartilhando diferentes visões de um mesmo fenômeno, neste caso, a prática e filosofia do ioga.

Foi realizada uma sessão de grupo focal semiestruturada, ou seja, com a organização e proposição de temas e intervenções por parte do pesquisador-moderador de modo a facilitar as trocas e manter os objetivos do trabalho. A sessão teve duração aproximada de uma hora e quinze minutos e foi conduzida pelo pesquisador responsável e sua equipe, que estiveram 
em contato constante com as participantes durante todo o programa, estabelecendo relações de confiança. Contudo, manteve-se o respeito a não diretividade (sem intervenções afirmativas ou negativas, emissão de opiniões ou conclusões) para, assim, estimular a discussão e, ao mesmo tempo, possibilitar que novos temas emergissem espontaneamente das participantes, como preconiza Gatti (2005).

A definição dos temas foi realizada a partir de relatos informais expressos pelas participantes ao longo do programa. Os temas explorados foram: dimensão da prática (questões gerais do programa, como conteúdo das aulas, incorporação dos exercícios na vida diária); dimensão física (percepção sobre melhora da capacidade física, como flexibilidade, força, resistência, agilidade e coordenação); dimensão saúde e doença (sono, ansiedade, alimentação, disposição, concentração, dores/desconfortos musculoesqueléticos, uso de medicação); dimensão social (interação com participantes do programa e do seu convívio); e dimensão psicoemocional (estado emocional antes e após as aulas).

A análise dos dados foi fundamentada na Análise de Conteúdo, que Bardin (2000, p. 38) define como "um conjunto de técnicas de análise das comunicações, que utiliza procedimentos sistemáticos e objetivos de descrição do conteúdo das mensagens". Acrescenta Triviños (1987) que essa análise sistemática permite reinterpretar as mensagens e compreender seus significados além da leitura comum. As três etapas de análise consistiram em: i) seleção e exploração do material (pré-análise); ii) codificação; eiii) agrupamento dos temas e categorização. Na seleção e exploração do material, foram selecionados os relatos já transcritos, em seguida foi realizada a leitura de cada um deles. Na codificação, foram identificados e marcados os diferentes temas no texto. $\mathrm{O}$ agrupamento dos temas (categorização) foi feito após a leitura dos temas previamente identificados nos relatos e selecionados aqueles que possuíam semelhança ou que estavam relacionados entre si. Os relatos foram agrupados nas seguintes categorias: i) melhoras clínicas e das capacidades físicas; ii) atitudes e posicionamento; iii) olhar para si autovalorização.

\section{ANÁLISE E DISCUSSÃO DOS RESULTADOS}

\subsection{Melhora clínica e da capacidade física}

nesta categoria são discutidas as percepções das mulheres sobre os efeitos da prática de ioga em relação às dimensões física, de saúde e doença, e a capacidade funcional para realizar atividades do cotidiano. Tais benefícios costumam ser os primeiros observados ao início dessa prática.

Atualmente, o ioga vem ganhando espaço como uma estratégia de tratamento não farmacológico associado ao tradicional para pessoas com hipertensão arterial, sendo que exercícios de respiração são recomendados pela VII Diretrizes Brasileiras de Hipertensão (MALACHIAS et al., 2016). Baseado no crescente aumento de evidências científicas apresentando resultados positivos com a prática de Hatha Yoga, o programa em questão teve como um dos objetivos a redução e controle da pressão arterial. Tais melhoras foram identificadas nos relatos de algumas participantes quando questionadas sobre 0 assunto: "a minha pressão, agora, vejo uma vez por dia, antes via três vezes por dia e vivia sempre com mal-estar", corroborando outros estudos reportados na literatura técnica (DAMODARAM et al., 
2002; MIZUNO; MONTEIRO, 2013; SIVASANKARAN et al., 2006; PINHEIRO et al., 2007), que demonstraram efeitos hipotensores dos exercícios de ioga.

Uma das mulheres participantes associou a melhora de um problema dermatológico, relacionado ao estresse, como resultado da prática do ioga:

Eu tenho vitiligo e eu nunca estive tão bem na vida com o vitiligo como tô agora, como esse ano. Por tudo que já passei esse ano de estresse, de problema era pra eu tá 'lotadinha' e eu não tô, muito pelo contrário, tô pigmentando cada dia mais, eu acredito que seja por isso, porque tratamento não tô fazendo nada (LAKSHIMI).

Não existe consenso sobre a etiologia do vitiligo, diferentes teorias são usadas para explicar a sua origem e acredita-se que fatores emocionais relacionados ao estresse têm relação com o desenvolvimento da doença (NOGUEIRA; ZANCANARO; AZAMBUJA, 2009; ROSA; NATALI, 2009). O relato acima mostra a possível contribuição da intervenção com ioga no tratamento complementar dessa patologia, além de outras comumente mencionadas na literatura, tais como hipertensão arterial e diabetes. Neste caso, a redução do estresse promovido pela prática, como citado por outros estudos (COWEN, 2010; MELVILLE et al., 2012; WOLEVER et al., 2012), pode estar associada à melhora do quadro.

As participantes também citaram, amplamente, melhora do condicionamento físico, principalmente no que se refere às atividades de vida diária. Importante atentar para este aspecto relacionado à capacidade física, já que sua manutenção é fundamental para assegurar a autonomia dos indivíduos, principalmente com as perdas advindas do processo de envelhecimento.

A melhora da flexibilidade é um dos benefícios mais visíveis do ioga (TUZUN et al., 2010; ZENATTI; LUZ; OLIVEIRA, 2013), pois com a prática de ásanas (posturas) decorre um relaxamento gradual dos músculos e tecidos que envolvem ossos e articulações, auxiliando também na manutenção da força muscular, protegendo de doenças como artrite, osteoporose e dores nas costas, que limitam a realização de tarefas simples do cotidiano.

Nesse sentido, destacou uma participante: "Eu não conseguia cortar a unha do pé" (GANESHA). Outra ainda contou: "eu vou no mercado e venho com aquelas sacolas [...] eu tinha que sentar porque as dores nas costas... É incrível, agora [...] eu chego em casa sem dor nenhuma!" (VISHNU). Tais relatos podem estar associados à prática regular de ásanas, os quais compreendem a maior parte das sessões de Hatha Yoga, sendo compostos por exercícios de alongamento, isometria e equilíbrio estático que podem resultar na melhora da postura, aumentando os níveis de força e consciência corporal. Além disso, representam um resgate da autoestima e da independência.

Ainda em relação a dor, Ferrari et al. (2015), identificaram que uma sessão de ioga não foi capaz de reduzir significativamente a percepção de dor em participantes jovens, mas a prática regular (uma ou duas vezes por semana), como a desenvolvida no presente estudo, promoveu redução significativa de dores musculoesqueléticas, diminuindo a interferência e as limitações causadas nas atividades do cotidiano, resultados semelhantes aos aqui encontrados. Os autores ainda ressaltam a diminuição do consumo de medicamentos analgésicos, outro aspecto que emergiu nos relatos das participantes: "Eu parei de ir na farmácia buscar remédio pra dor, eu parei definitivamente!" (VISHNU). 
A capacidade cardiorrespiratória foi outro ponto destacado pelas participantes, como observado no relato: "Eu tava com uma dificuldade imensa, quando eu chegava no segundo andar eu sentia falta de ar e agora eu percebi... que eu já tô correndo, subo a escada correndo e sem canseira" (DURGA).

Assim, destacou-se a percepção das participantes em relação à melhora na resistência muscular, flexibilidade, agilidade e capacidade cardiorrespiratória. Tais capacidades são responsáveis pela aptidão de realizar movimentos diários com maior ou menor facilidade, como, por exemplo, apertar os sapatos, pentear o cabelo, alcançar objetos, dentre outros (FIDELIS; PATRIZZI; WALSH, 2013).

A manutenção e a melhora da capacidade física resultaram, também, na ampliação da consciência corporal, como destacou uma participante: "A gente aprendeu a descobrir as funções de cada tendão, de cada músculo, agora é esse. A gente usa sim conscientemente" (SHIVA). Segundo estudo de Teixeira e Cardoso (2009), as posturas do ioga, quando supervisionadas por profissional qualificado, promovem tanto benefícios relacionados à percepção, alinhamento postural, integração dos movimentos, como também respeito e descoberta dos próprios limites, estabilidade, diminuição do esforço de forma gradativa para permanecer em uma determinada postura em estado de conforto, bem como controle muscular na ativação e relaxamento e controle seletivo dos grupos musculares.

Além das posturas (ásanas) que incidem mais diretamente nas condições físicas, o entendimento de princípios filosóficos como saucha, que significa pureza de pensamentos, atitudes e desintoxicação do corpo, levam a um processo de melhor reconhecimento, pensamentos positivos e seleção inteligente da alimentação. Outro princípio filosófico é o tapas, que se refere ao esforço de superação e à autodisciplina, que pode levar os praticantes a adotar de maneira efetiva as orientações dos professores do programa e também dos profissionais de saúde.

Os exercícios de flexibilidade em conjunto com a concentração mental e respiração profunda e compassada, na qual se utilizam o abdômen e o tórax de forma consciente e ativa, possibilitam a ligação entre os hemisférios direito e esquerdo do cérebro, sendo que 0 indivíduo se torna mais tranquilo e consegue, de forma persistente, alcançar um estado interno de autoconhecimento e consequentemente equilíbrio das emoções e sentimentos (ALVES; BAPTISTA; DANTAS, 2006).

A análise dos dados nesta categoria demonstra importantes benefícios do ioga relacionados com o bem-estar físico, no que diz respeito à melhora de condições gerais de saúde, como a redução da pressão arterial e do consumo de medicação e melhora de capacidades e habilidades que permitiram desempenhar atividades do cotidiano consideradas básicas, mas que muitas das participantes já não realizavam.

Ressalta-se que tal equilíbrio também pode ser potencializado com a reflexão em torno dos yamas e nyamas, os princípios éticos do ioga, e levar a mudanças de atitude e comportamento, tanto em relação a si próprio como em relação ao seu entorno, como discutido na sequência. A melhora da capacidade física e da percepção geral de saúde aumenta 0 estado de bem-estar físico, acarretando mudanças gerais, como comportamentos e atitudes positivas. 


\subsection{Atitudes e posicionamentos}

O processo de autoconhecimento, derivado de um nyama conhecido por svadhyaya (FEUERSTEIN, 1998), inerente à prática de ioga, pode promover mudanças atitudinais e comportamentais que refletem na forma de agir e se relacionar com as pessoas e mudar 0 padrão de respostas e reações a diferentes situações do cotidiano. Essas mudanças podem ser atribuídas ao conjunto de técnicas de ioga, que nos leva a defrontar-nos com o corpo (magro, gordo, alto, esguio etc.), emoções (alegria, tristeza, raiva, paciência, medo, inveja etc.) e atitudes (curiosidade, compaixão, motivação, autocuidado), promovendo o processo de identificação e aceitação das individualidades (santosha, cultivo do contentamento).

Segundo Taimni (2004), os yamas e nyamas têm como objetivo eliminar todas as perturbações mentais e emocionais. Assim, acreditamos que a compreensão e prática dos princípios éticos podem ter proporcionado às mulheres participantes melhor controle emocional, auxiliando a minimizar os efeitos do estresse, pois nos relatos emergiu: "Eu chorava muito, qualquer coisinha eu abria a boca, escondidinho [...] e você sabe que cê falando agora, faz um tempão que não dá vontade de chorar" (LAKSHIMI).

Em estudo recente, Lindahl et al. (2016) apresentaram que a prática por sete semanas de Hatha Yoga melhorou significativamente a percepção de idosos sobre o bem-estar mental/ emocional, níveis de exaustão e os níveis de estresse percebido. Tais melhoras também foram encontradas no grupo focal, como ilustra uma participante:

No conhecer-se, o físico da gente, já é motivo de você liberar a ansiedade. Porque você conhece, alguém fala alguma coisa, você fala 'o que vem de fora não tem que me prejudicar, eu me conheço [...]' você se dá a resposta, você já não estressa mais (VISHNU).

Outros aspectos emocionais são refletidos nas atitudes das participantes: "Os grandes problemas diminuem" (SARASWATI); alterando posicionamentos diante de situações adversas: "É, a gente não pode mudar o mundo, mas a gente pode mudar nossa reação, a nossa postura perante o mundo" (SHIVA). Sabe-se que um dos benefícios da prática de atividades físicas tradicionais é o aumento da autoconfiança e melhora da autoimagem, e 0 ioga também proporcionou a essas mulheres mudanças nestes aspectos: "A gente aprende se defender, né?! Com a ioga, a gente aprende a se defender de qualquer situação" (KALI); podendo gerar mudanças profundas: "Então, vai fazer parte da minha vida pra sempre, porque eu notei que em mim muita coisa que mudou, uma autoconfiança, eu achei que agora eu posso, né?!" (GANESHA).

Além disso, alterações de atitudes e da forma de se posicionar possibilitam melhoras nas relações sociais: "A implicância [...] porque você tava ligado em outra esfera e agora acho que a vida vai mais mansa" (SHIVA); e observadas também no âmbito familiar:

Meus filhos mesmo falam 'Mãe, a senhora foi na ioga, a senhora tá diferente. É, tá mais alegre, mais tudo', porque eu não converso, né?! Até nisso eu tô assim, sabe, 'Nossa, a Senhora agora tá conversando', porque eu sou meio tímida, então nem em casa eu também não... eles só falam 'Nossa, fez bem para a senhora!' (SATI).

O ioga contribui para proporcionar uma nova forma de encarar os problemas cotidianos a partir da experiência com a prática dos ásanas. Durante a aula eram realizadas posturas 
desafiadoras, que geravam desconforto pelo alongamento ou força e equilíbrio, e que permitiam refletir sobre a forma como cada uma se comportava frente a esses desafios e, assim, compreendiam os próprios padrões mentais, como expresso no seguinte relato: "Eu utilizo aquilo na vida, não é só no dia do exercício, porque me ajuda a controlar os meus problemas que não eram entendidos e agora são" (SHIVA).

A compreensão dos yamas e nyamas promoveu percepções de mudanças nas atitudes das participantes de forma significativa, ampliando o entendimento de como eram as próprias reações diante de determinados fatos do cotidiano e questões existenciais, levando à adoção de uma nova postura consciente e equilibrada.

No Hatha Yoga o ritmo da aula é alternado com posturas desafiadoras e outras de descanso ou relaxamento, o que proporciona o direcionamento da atenção para processos internos, indicando que mesmo as situações difíceis são passageiras, gerando um novo olhar sobre a própria vida.

\subsection{Olhar para si - autocuidado}

investimento em saúde e o desenvolvimento das percepções de si não dependem exclusivamente de elementos subjetivos, são interdependentes do contexto social no qual 0 indivíduo está inserido, tais como acesso a atendimentos básicos em saúde, alimentação, transporte, educação, entre outros. Particularmente, o autocuidado, na definição do Ministério da Saúde (BRASIL, 2017), se refere ao conjunto de ações que o indivíduo realiza em relação a si mesmo, em busca de manter ou ampliar sua saúde e bem-estar, como pensar sobre o estilo de vida, assumir hábitos saudáveis em relação à alimentação, à atividade física e ao lazer, que possam auxiliar na prevenção e/ou evitar complicações de algumas doenças. Se refere a olhar para si, observar e escolher ações e formas para cuidar da sua saúde.

A maioria das participantes era aposentada e dedicava-se, em grande parte do tempo, ao cuidado com os filhos, netos e marido. Relataram sentir dificuldades em reservar algum momento de sua rotina para voltar o olhar para si mesmas e investir no autocuidado: "Nossa, no começo foi meio estranho até pra mim, eu me sentia até meio culpada" (KRISHNA). Para esta participante, o deslocamento da atenção para si refletiu em sentimento de culpa, já que, para tanto, era preciso equilibrar o tempo entre os cuidados com a família e consigo.

O bom relacionamento com o professor-pesquisador, equipe e com as colegas foi relatado por algumas participantes, que expressaram a sensação de acolhimento, de fazer parte de uma família, de receber carinho e educação, fazendo com que elas se sentissem bem em fazer parte do grupo. Essas percepções podem ter contribuído para a manutenção das participantes no programa, já que no início algumas relataram dificuldade em colocar em segundo plano suas tarefas cotidianas, como supracitado.

Não obstante, após frequentarem o programa, passaram a se importar mais consigo mesmas: "Não posso, agora eu tenho compromisso. Eu tenho que ir no ioga terça, quarta e sexta" (KRISHNA). Cuidar da própria saúde vai ao encontro de vários princípios do ioga, mas podemos identificar essa atitude como ahimsa (não violência), no sentido de não negligenciar a saúde, expondo-se a algum tipo de dano. Portanto, cuidar da saúde é uma forma de não violência. 
Estudo de Gomes-Villas Boas et al. (2011) com homens e mulheres ( $\geq 40$ anos) com diabetes mellitus tipo II apresentou baixa adesão às atividades de autocuidado (dieta e exercícios físicos). Porém, no grupo do presente estudo a adesão às atividades de autocuidado foi expressiva, sendo citada na maioria dos relatos. Acreditamos que a compreensão e o estudo sobre os princípios filosóficos do ioga, como svadhyaya, que diz respeito ao autoestudo, e tapas (disciplina, autossuperação ou esforço) podem refletir nestas atitudes das participantes: "A gente marca encontro consigo mesmo, essa hora, esse espaço é meu! A gente não deixa nada interferir porque tem um horário" (SHIVA).

Essa compreensão pode levar a mudanças de hábitos no estilo de vida, como 0 engajamento em outras atividades físicas, para além das práticas de ioga:

Eu tinha resistência de fazer qualquer atividade física! Eu não fazia, eu começava, fazia um mês e parava, uma hidroginástica, uma caminhada... caminhada era três, quatro dias eu parava. Depois que eu comecei fazer a ioga, eu gostei tanto da ioga, que eu faço caminhada porque eu venho na ioga. Se eu fosse só caminhar eu não caminharia, mas como eu venho pra ioga, eu venho caminhando e eu sinto prazer em vir. [...] Então melhorou, assim, a vontade! Além da caminhada eu consegui fazer hidroginástica, tô fazendo também. Uma foi puxando a outra (GANESHA).

A prática de ioga, em função de suas características, nos permite entrar em contato com o silêncio e isso pode propiciar momentos nos quais se torna possível um olhar interior, promovendo a auto-observação: "Acho que dá segurança, do 'eu posso', né?! Então você vai tentando 'pô, eu consegui, nossa' e isso a gente leva" (KRISHNA). Os princípios éticos e morais do ioga, primeiros passos do Yoga Sutra de Patañjali, são componentes intrínsecos presentes no ambiente de aula que podem ser incorporados pelos praticantes, o que possivelmente faz desencadear um processo de revisão de valores e reflexão, possibilitando 0 autoconhecimento.

Além do autocuidado, as participantes conscientizaram-se da necessidade de mudanças no entorno e, assim, passaram a ensinar e a incentivar mudanças de hábito para pessoas próximas, como alongar e espreguiçar, caminhar e se envolver com outros exercícios: "A minha irmã tomava remédio pra dormir, pouquinho, mas tomava, eu falei 'Irmã, por que você não tenta fazer respiração assim, assim, assim?' Não é que ela parou de tomar remédio?!" (KRISHNA). Pesquisa de Steffens et al. (2013) demonstra que 32 sessões da prática conjunta de caminhada e ioga foram capazes de gerar melhoras significativas na qualidade do sono.

As participantes relataram que os novos hábitos de pessoas próximas a elas não ficaram restritos apenas às técnicas do ioga: "E, por causa de tudo isso, minha filha, que sempre foi sedentária, muito estudiosa, só trabalha e estuda, entrou, tá fazendo pilates, contou pra mim toda... eu falei 'Ah, que coisa boa'" (KRISHNA).

A proposta do ioga como filosofia de vida foi incorporada pelas participantes, gerando um olhar interessante sobre o processo de envelhecimento:

A ioga faz a gente descobrir que a gente não precisa ser velho, a ruga é outra coisa, não é velhice, velhice é você não se mexer mais, não fazer aquilo que deve, perder suas habilidades, não cortar a unha do pé, sabe isso... a gente põe o pé aqui [levando o pé em direção à testa]. Então, eu acho que isso é uma manutenção maravilhosa! É um envelhecer mais doce (SHIVA). 
Esse relato é o reflexo de santosha (contentamento, alegria) e de isvara-pranidhana (entrega ao caminho espiritual) sobre o curso da vida, aceitando com alegria cada uma das fases do ser humano.

A prática de ioga, segundo os oito passos sistematizados por Patãnjali, envolve 0 ser humano de forma integral, permitindo que cada um acesse sua condição essencial. 0 "olhar para si", longe de ser um ato egocêntrico, está relacionado com o autoconhecimento e desperta o indivíduo para o autocuidado, 0 amor próprio e o empoderamento como meios para o desenvolvimento pessoal, refletindo assim na maneira como a pessoa se relaciona com familiares e amigos e os cuidados dispensados a eles.

\section{CONSIDERAÇÕES FINAIS}

O objetivo deste estudo consistiu em analisar as percepções de mulheres adultas e idosas sobre as mudanças nas condições de saúde, atitudes e comportamentos relacionadas à prática de Hatha Yoga pelo período de um ano.

As análises dos relatos apresentados pelas participantes indicam que a prática regular de Hatha Yoga proporcionou a aprendizagem e incorporação das posturas (ásanas) no dia a dia, auxiliando o processo de torná-las mais conscientes e autônomas em relação aos cuidados com a saúde física, tais como a alimentação, o exercício físico e o repouso ou relaxamento. 0 contato e o entendimento dos conceitos filosóficos do ioga e sua aplicação na rotina cotidiana podem ter refletido na forma de enfrentar as situações e os problemas pessoais, nas relações familiares e sociais, além de proporcionar um novo olhar sobre si mesma, em relação ao autocuidado, às atividades prazerosas e à sua individualidade.

O programa pautado na integralidade do indivíduo possibilitou o desenvolvimento de atitudes e comportamentos que impactaram na percepção da saúde física, mental, emocional e social das participantes. Conclui-se, de acordo com as evidências qualitativas apresentadas e discutidas no presente estudo, que o ioga representa um importante recurso terapêutico para a saúde e bem-estar do ser humano.

Neste estudo foi possível analisar as percepções relacionadas à prática de ioga em diálogo com a produção da literatura relacionada à temática, ressaltando que são poucos os estudos fundamentados na perspectiva qualitativa de análise, no campo do ioga, e que tenham como lugar de fala os(as) próprios(as) participantes. Diante dos achados neste estudo, investigações futuras podem explorar outros olhares fundamentados em referenciais teóricos das Ciências Humanas e Sociais, contribuindo para a contínua construção do conhecimento nesta área.

\section{REFERÊNCIAS}

ALVES, Audrey dos Santos; BAPTISTA, Marcio Rodrigues; DANTAS, Estélio Henrique Martin. Os efeitos da prática do ioga sobre a capacidade física e autonomia funcional em idosas. Fitness \& Performance Journal, v. 5, n. 4, p. 243-249, 2006.

ANDRE, Marli Elisa Dalmazo Afonso de. Etnografia da prática escolar. Campinas: Papirus, 1995. 
BARDIN, Lawrence. Análise de Conteúdo. Lisboa: Edições 70, 2000.

BARROS, Nelson Filice et al. Yoga e Promoção da Saúde. Ciência e Saúde Coletiva, v. 19, n. 4, p. 1305-1314, 2013.

BOGDAN, Robert C.; BIKLEN, Sari Knopp. Investigação qualitativa em educação: uma introdução à teoria e aos métodos. Porto: Porto, 1999.

BRASIL. Ministério da Saúde. Departamento de Atenção Básica. Autocuidado. Disponível em: $<$ http://dab. saude.gov.br/portaldab/autocuidado.php>. Acesso em: 28 jun. 2017.

BUFFART, Laurien M. et al. Physical and psychosocial benefits of yoga in cancer patients and survivors, a systematic review and meta-analysis of randomized controlled trials. BMC Cancer, v. 12, n. 12, p. 559, 2012.

CHEN, Kuei-Min et al. Sleep quality, depression state, and health status of older adults after silver yoga exercises: cluster randomized trial. International Journal of Nursing Studies, v. 46, n. 2, p. 154-163, 2009.

COWEN, Virginia S.; ADAMS, Troy B. Physical and perceptual benefits of yoga asana practice: results of a pilot study. Journal of Bodywork and Movement Therapies, v. 9, n. 3, p. 211-219, 2005.

COWEN, Virginia S. Functional fitness improvements after a worksite-based yoga initiative. Journal of Bodywork and Movement Therapies, v. 14, n. 1, p. 50-54, 2010.

DAMODARAN, Aswath et al. Therapeutic potential of yoga practices in modifying cardiovascular risk profile in middle aged men and women. The Journal of the Association of Physicians of India, v. 50, n. 5, p. 633-640, 2002.

DIAS, Cláudia Augusto. Grupo focal: técnica de coleta de dados em pesquisas qualitativas. Informação \& Sociedade, v. 10, n. 2, p. 1-12, 2000.

FERRARI, Marie-Louise Gander et al. Expectations and effects of a single yoga session on pain perception. International Journal of Yoga, v. 8, n. 2, p. 154-157, 2015.

FEUERSTEIN, Georg. A tradição do Yoga. São Paulo: Pensamento, 1998.

FIDELIS, Luiza Teixeira; PATRIZZI, Lislei Jorge; WALSH, Isabel Aparecida Porcatti de. Influência da prática de exercícios físicos sobre a flexibilidade, força muscular manual e mobilidade funcional em idosos. Revista Brasileira de Geriatria e Gerontologia, v. 16, n. 1, p. 109-116, 2013.

GATTI, Bernadete Angelina. Grupo focal na pesquisa em Ciências Sociais e Humanas. Brasília: Líber Livro, 2005.

GOMES-VILLAS BOAS, Lilian Cristiane et al. Adesão à dieta e ao exercício físico das pessoas com diabetes mellitus. Texto \& Contexto-Enfermagem, v. 20, n. 2, p. 272-279, 2011.

KALYAMA, Acharya. Yoga-Repensando a Tradição. São Paulo: Ibrasa, 2003.

LINDAHL, Eric et al. Yoga reduces perceived stress and exhaustion levels in healthy elderly individuals. Complementary Therapies in Clinical Practice, v. 24, p. 50-56, 2016.

MALACHIAS, Marcus Vinícius Bolívar et al. $7^{a}$ Diretriz brasileira de hipertensão arterial. Arquivos

Brasileiros de Cardiologia, v. 107, n. 3, supl. 3, p. 1-83, 2016. 
MELVILLE, Geoffrey W. et al. Fifteen minutes of chair-based yoga postures or guided meditation performed in the office can elicit a relaxation response. Evidence-Based Complementary and Alternative Medicine, v. 2012, 2012. Disponível em: <https://www.hindawi.com/journals/ ecam/2012/501986/>. Acesso em: 12 jun. 2017.

MIZUNO, Julio; MONTEIRO, Henrique L. An assessment of a sequence of yoga exercises to patients with arterial hypertension. Journal of Bodywork and Movement Therapies, v. 17, n. 1, p. 35-41, 2013.

MIZUNO, Julio et al. Percepção de mulheres com hipertensão sobre a prática de ioga na saúde e na qualidade de vida. Revista Brasileira de Atividade Física \& Saúde, v. 20, n. 4, p. 376-385, 2015.

MORGAN, David L. Focus group as qualitative research: Qualitative Research Methods. Londres: Sage, 1997.

NOGUEIRA, Lucas S. C.; ZANCANARO, Pedro C.Q.; AZAMBUJA, Roberto D. Vitiligo e emoções. Anais brasileiros de dermatologia, v. 84, n. 1, p. 41-45, 2009.

PATTON, Michael Quinn. Qualitative research and evaluation methods. London: Thousand Oaks: Sage, 2002.

PINHEIRO, Carlos Hermano da Justa et al. Uso do ioga como recurso não-farmacológico no tratamento da hipertensão arterial essencial. Revista Brasileira de Hipertensão, v. 14, n. 4, p. 226232, 2007.

ROSA, Eliane Cristina; NATALI, Maria Raquel Marçal. Vitiligo: um problema que não pode passar em branco. Saúde e Pesquisa, v. 2, n. 1, p. 119-126, 2009.

SHARMA, Ratna; GUPTA, Nidhi; BIJLANI, Ramesh Lal. Effect of yoga based lifestyle intervention on subjective well-being. Indian Journal of Physiology and Pharmacology, v. 52, n. 2, p. 123-131, 2008.

SIVASANKARAN, Satish et al. The effect of a six-week program of yoga and meditation on brachial artery reactivity: Do psychosocial interventions affect vascular tone?. Clinical Cardiology, v. 29, n. 9 , p. 393-398, 2006.

STEFFENS, Ricardo de Azevedo Klumb et al. Efeito da prática conjunta da caminhada e yoga no sono, depressão e qualidade de vida em pacientes com síndrome da fibromialgia. ConScientiae Saúde, v. 12, n. 3, p.371-378, 2013.

TAIMNI, Iqbal Kishen. A ciência do Yoga. Brasília: Teosófica, 2004.

TEIXEIRA, Ana Claudia Tonelli; CARDOSO, Tuane Bernardo. Efeitos da prática de yoga em indivíduos pertencentes ao espaço terapêutico shankara do município de Tubarão-SC. 95 f. 2009. Trabalho de conclusão (Fisioterapia) - UNISUL, Tubarão-SC, 2009.

TUZUN, Sansin et al. Yoga might be an alternative training for the quality of life and balance in postmenopausal osteoporosis. European Journal of Physical and Rehabilitation Medicine, v. 46, n. 1, p. 69-72, 2010.

TRIVIÑOS, Augusto Nibaldo Silva. Introdução à pesquisa em Ciências Sociais: a pesquisa qualitativa em educação. São Paulo: Atlas, 1987.

WOLEVER, Ruth Quillian et al. Effective and viable mind-body stress reduction in the workplace: a randomized controlled trial. Journal of Occupational Health Psychology, v. 17, n. 2, p. 246-258, 2012. 
ZENATTI, Adriana; LUZ, Ana Cristina da; OLIVEIRA, Rochelli Vilma de. Efeitos na flexibilidade e força de mulheres fisicamente ativas resultantes da prática de um programa de treinamento de 2 meses de Hatha Yoga, modalidade Jayaprána Yoga. Revista Brasileira de Obesidade, Nutrição e Emagrecimento, v. 5, n. 30, p. 418-426, 2013.

Apoio:

O presente trabalho foi realizado com apoio da Coordenação de Aperfeiçoamento de Pessoal de Nível Superior (CAPES) e da Pró-reitoria de extensão da UNESP. 